\title{
Editorial
}

\section{Painful excavations: extractivism, dispossession, rights and resistance}

This edition of the Journal of Human Rights and the Environment offers a multidisciplinary - and at times deeply visceral - encounter with painfully familiar arcs and dynamics of eco-injustice.

It presents an enriching, sustained and at times deeply moving set of reflections on the juridical constitution of agency and ethical significance and the systematic denial of both - often in service of extractivism. Themes emerging include the dense imbrication of extractivism and well-honed practices of colonial and neo-colonial dispossession, including examination of the multiple layers of such dispossession: force; fraud; legal fiat; legal failure; epistemic exclusion; the eco-violative implications of the ontological cleavage grounding juridical hierarchies of being and value. At the same time, the articles also offer accounts of modes of resistance. Some draw on rights and legislative opportunities as modes of (albeit compromised and complex) resistance, while others draw on arts practices and interdisciplinary explorations of mining, expulsions and grief.

A relatively consistent theme in many of the contributions is the marginalization - and in some cases the outright denial - of Indigenous agency and/or the exclusion of community voices and concerns. Erin Fitz-Henry, in 'Distribution without representation? Beyond the rights of nature in the southern Ecuadorian highlands' records the systemic exclusion of affected communities in Ecuador from decision-making processes. These processes, she argues, are monopolized by state ministries - but in response there is a promising proliferation of new forms of resistance in the form of litigant claim-making practices and demands for representation. Ecuador might have the most biocentric constitution in the world, Fitz-Henry notes, but it has intensifying levels of national investment in extractive development projects, and it is precisely this intensification that has driven affected frontline communities to seek participation in decision-making processes. Drawing on her ethnographic research concerning the Río Blanco gold and silver mine in the southern highland province of Azuay, Fitz-Henry explores the ways in which environmental rights are now being used to challenge decision-making monopolies. She argues that despite the much-lamented failure of rights-based approaches to displace extractivist imperatives, rights-based approaches, when deployed as part of wider social struggles for representation in decision-making processes, appear to possess the potential to generate change. 'Rights of nature', it seems, have potential, therefore, as mechanisms for representational justice.

In 'The 2017 Inter-American Court's Advisory Opinion: changing the paradigm for international environmental law in the Anthropocene', Maria Antonia Tigre and Natalia Urzola also see signs in the Americas suggesting the emergence of new, resistive jurisprudential approaches. This time, it is the Inter-American Court of Human Rights that promises juridical innovation in search of eco-justice. In 2017, the Court 
issued a landmark Advisory Opinion recognizing the right to a healthy environment as being 'fundamental to the existence of humanity'. The 'groundbreaking' Opinion confirmed extraterritorial jurisdiction for transboundary environmental harms; the autonomous right to a healthy environment; and State responsibility for environmental damage both within and beyond the State's borders. The authors argue that the Opinion is significant because it promotes the development of international jurisprudence on cross-border and diagonal international human rights obligations, while, importantly, the autonomous nature of the right to a healthy environment protects 'features of nature' as having 'intrinsic value'. The authors argue that this formulation of the right to a healthy environment suggests that the Advisory Opinion has opened a juridical route towards confirming the rights of nature. Indeed, the authors finish by drawing attention to a 2020 case that already demonstrates the promising impact of the Opinion on litigation strategies. Such developments augur potentially effective forms of environmental claim-making ahead.

Matters, however, are rarely straightforward as concerns rights-based action and argument. In 'Environmental struggles in Aboriginal homelands: Indigenizing conservation in Australia', Freya Mathews discusses fractious dilemmas concerning tensions between conservationism and Indigenous aspirations for development: Indigenous homelands, Mathews notes, contain many large areas of high conservation value, and conservationist attempts to protect them sometimes conflict with the aspirations of Indigenous populations to benefit from development of the land. Framing this dilemma as being a core tension between conservationist commitments to ecological justice and traditional owner commitments to Indigenous justice, Mathews refracts the issues through the lens of a case study of a proposed natural gas installation at James Price Point in the far north of Western Australia. Mathews argues for resolution of the dilemma through what she calls the 'Indigenization' of conservation. This would be a significant 're-visioning' of conservation that might mean conservationists and environmentalists conceding to Aboriginal communities 'the moral ownership of conservation per se, at least as it applies to Aboriginal homelands, and perhaps more widely'. Such a shift might facilitate an ecocentric approach that respects and is shaped by Aboriginal Law and culture rather than promoting an ecocentrism conditioned by mainstream onto-epistemic commitments.

It is not difficult to detect in Mathew's argument a sense in which respect for Indigenous law and culture could be given a level of recognition that could resist a quasi-colonial ecocentrism that runs the risk of re-installing Eurocentric onto-epistemic dominance: a conservationism that marginalizes Indigenous development aspirations runs the risk of locking Indigenous communities into a relatively static Euro-imaginary concerning their assumed primitivism. And, if that were to be the case, it would hardly be the first time that Eurocentric assumptions have operated to deny Indigenous agency and to dismiss Indigenous orders of meaning. Indeed, such denial was fundamental to the violation of embedded Indigenous relations with ancestral lands and waters in the service of capitalist colonial extractivism.

Extractivism in both its historical and contemporary manifestations forms the critical focus of the next five contributions to this edition - along with what extractivism implies concerning Indigenous dispossession.

These five contributions emerged from one interdisciplinary project - an art, science and theory project called Still Lives: a beautiful science.

The first contribution is an introduction by Lee Harrop and Jana Norman, the project's two key co-initiators. As Harrop and Norman note, all five contributions are directly associated with the project. The contributions include artist statements from 
Harrop about the mining core sample artworks she created for Still Lives and from Katerina Teaiwa about her artwork Project Banaba, which exposes the colonial legacy of phosphate mining on the Pacific island of Banaba. The other two contributions are from Norman (a legal theoretical article engaging with Harrop's mining core sample artwork) and from humanities scholar Mandy Treagus, another participant in the Still Lives project, who contributes an article tracing the history of dispossession lying behind Teaiwa's Project Banaba.

In her artist statement, Lee Harrop introduces the Still Lives project and explains its ontological and epistemological underpinnings. Still Lives, she explains, was an artscience project that drew together geologists, a petrologist, environmental scientists, philosophers, legal theorists, writers, artists, composers and musicians. Its central focus was on key social and philosophical questions about the arts and sciences of mining - explored by Harrop herself through mining core samples.

Jana Norman's legal theoretical reflection directly engages with Harrop's work. In 'An engraved invitation to consider human-earth relations: thinking non-dualism through the mining-based art practice of Lee Harrop', Norman invites her readers to mine the ontological assumptions underlying extractivism itself. She notes the enormity of mining's impact on human rights and the environment and the scale and ubiquity of globalized industrial mining. Linking this scale to consumer demand for mined materials in technical applications, Norman sets out to 'focalize a range of contentious issues and complexities'. Mining, for Norman, is a paradigmatic instance of instrumentalism ultimately resting on the reason/nature dualism underlying mainstream Western ontology. Deploying the critical ecological feminism of Val Plumwood, Norman traces the structural features of this dualism and offers an alternative imaginary, one combining critical ecological feminist insights with a broadly new materialist 'onto-ethico-epistemology of agential realism'. It is against this theoretical background that Norman explores Harrop's art as a site for thinking through the theoretical implications of her own argument. Norman is explicit about her decolonial ambitions: she seeks to forge a space of new, open epistemic engagement with a 'better story', one rejecting the 'further colonization of the knowledge, wisdom and experience of ... women, indigenous cultures, nature itself'.

In 'Artist statement', Katerina Teaiwa provides an intimate personal account of her Project Banaba. Opening with words from her sister Teresia's poem ('Agriculture is not in our blood, but our blood is in agriculture'), Teaiwa introduces her work as a conceptually layered, multimedia experience: a rich visual narratology exposing the profound colonial injustices enacted upon the Banaban people and the rock of Banaba itself, 'te aba, the body of the land and the body of the people'. The extraction of phosphate was more than the extraction of a mere 'resource': it was the extraction of the Banabans from their entire way of life; their extraction from their island; even the extraction of the bones of their ancestors. These ancestral bones were then dispersed through the transportation and distribution of agricultural fertilizer to feed the populations of the very nations that had so decimated Banaba. Layering her account with the sense of her own layered identities, Teaiwa offers a haunting descendant's testimony based on over 20 years of research in the National Archives of Australia. Her final words tellingly capture the violence and the tragedy of the plunder of Banaba: 'What took millions of years for the earth, avian and marine life to build up as phosphate rock, and over 2000 years for the Banabans to infuse with their lives, bones, stories and memories, took capitalism, colonialism and mass agriculture just 80 years to decimate'.

It is this story of decimation that Mandy Treagus opens out in her rich and moving historical account of the Banaban dispossession and her reflection on Teaiwa's work. 
In 'Flight of the frigate bird: Ocean Island, phosphate mining and Project Banaba', Treagus offers a critical account of the environmental disaster enacted by phosphate mining on Banaba (or 'Ocean Island' as non-Banabans referred to the island). Treagus exposes the tactics used by what later became the British Phosphate Commissioners (BPC) - tactics in the service of an 80-year long process of extraction that resulted in the removal of 90 per cent of Banaban soil and in the alienation of Banabans from their land, livelihoods and culture. Treagus reflects on the ongoing legacy of Banaban bitterness and grief, recounting Banaban efforts to gain legal restitution for the harms visited upon them. And it is against this background that Treagus explores Teaiwa's Project Banaba art installation as a response to Banaban histories of dipossession. Finally, Treagus suggests that the Banaban case (sometimes cited as a test case for climate-induced migration) was a highly particular experience of loss intensified by the inseparability between Banaban identity and Banaban land ownership - ownership that took a distributed and inclusory form - a normative and physical intimacy with the body of Banaba itself. Treagus ends her article with a mournful reiteration of the way in which Banaban ancestors were - and remain - dispersed across the world through the distribution of their mined remains.

This final collection of articles thus brings a particular intimacy to the themes emerging in the earlier contributions to the edition. The various excavations, extractions and dispossessions haunting the edition as a whole are not easily ameliorated or recompensed. Despite this sense, however, it is the very non-fungible particularity of emplaced relationalities between peoples and lands - so central to this edition - that demands renewing forms of respect, commands the visibility of invisibilized suffering, and calls out for new juridical approaches to resist legitimated forms of organized plunder.

Anna Grear

Editor in Chief, Professor of Law and Theory, Cardiff Law School 